\title{
O HERDO DE CUNQUEIRO NA POESÍA DOS 80
}

Xosé María Álvarez Cáccamo

Escritor e crítico

doi:10.17075/mucnoc.2014.043 

Forcadela, M. / T. López / D. Vilavedra (coords.) (2014): Mil e un cunqueiros. Novas olladas para un centenario, Santiago de Compostela, Consello da Cultura Galega. doi:10.17075/mucnoc.2014. pp. 857-870

Todo pende en que ún esteña morto perguntando pola herba que nasce derriba

Preguntamos pola herba que nace derriba. Teimamos na posición inquisitiva do autor de Herba aqui e acolá , que se sońou integrado no "pasteiro comunal / onde brancas ovellas alindadas por unha vella / pacen seguido sen erguer a cabeza / sin decatarse de ónde vén a herba / que moen e remoen os dentes apertados». Pero non é o destino do corpo físico do poeta repartido en mínimas unidades de materia vexetal o que motiva a nosa inquisición. Preguntamos pola herba que nace derriba do texto literario de Álvaro Cunqueiro. Queremos decatarnos de como vai e vén o curso do seu legado, herba aquí e acolá a medrar na obra dos escritores que se alimentaron algunha vez coa substancia daquel herdo.

Afortunada metáfora a do herdo literario, que abre luces de sentido cara ao campo polisémico no que o termo se desenvolve en usos non especializados:

- dereito de recibir un conxunto de bens despois da morte do seu titular.

- conxunto de bens ou dereitos que se reciben despois da morte do seu titular.

- conxunto de características fisiolóxicas e anatómicas que os seres vivos reciben dos seus proxenitores.

- propiedade grande correspondente a unha soa persoa; herdade composta pola casa, as terras, o gando, etc.

O herdo literario constitúe tamén un dereito dos sucesores. Exercemos ese dereito, a posesión como propiedade inalienábel da parte que nos correspondeu da obra de determinados autores aos que limos con especial dedicación, sen risco de convertérmonos en obxecto de denuncia crítica, sempre que non confundamos a utilización da herdanza como instrumento de labor destinado a fertilizar o campo da obra propia co impúdico exercicio de imitación ou plaxio. Non resulta sempre doado, non obstante, establecer o perfil dos lindes que separan territorios

1 A. Cunqueiro: Herba aqui e acolá, en Obra en galego completa, Poesía. Teatro, I, Vigo, Galaxia, 1980. 
imitativos daqueloutros dotados de entidade singular, onde medra a herba de diversas tradicións incorporadas e interpretadas. Cómpre diferenciar o lexítimo usufruto da herdanza da reprodución mimética; ou a repetición incontrolada e inconsciente de fórmulas de coincidencia literal do seguimento voluntario das propostas dunha determinada escola. Obviamente, con esta esencial advertencia, de común cońecemento, non fica máis que enunciada a complexidade dos rumbos que debe percorrer unha lectura crítica atenta a contornar a xeometría do herdo.

O herdo literario non procede maiormente da transmisión dun legado recońecíbel polo sucesor. Así como dos devanceiros e proxenitores recibimos ese conglomerado (inabarcábel na súa totalidade pola conciencia) de características fisiolóxicas e anatómicas que nos retratan como estirpe e, en azaroso xogo combinatorio, conforman a nosa singularidade dun monumental e difuso conxunto de tradicións universais, herdamos unha inmensa propiedade, da que conseguimos identificar con certeza só algúns espazos cos que nos sentimos máis familiarizados. A herdade, esa propiedade correspondente a unha soa persoa que constitúe a obra literaria de cada quen, é o resultado da conxunción do herdo procedente da tradición coa transmisión de legados particulares. Pero tamén do diálogo entre herdeiros, do intercambio de bens que se realiza en vida dos coetáneos. Estamos a falar, pois, do intertexto, ese pasteiro comunal, da latencia permanente da tradición e da conversa incesante entre textos que conforman o feito literario. $\mathrm{O}$ herdo, considerado como recepción e asimilación de códigos literarios anteriores, constitúe unha das formas máis activas da intertextualidade.

Se nos preguntamos pola herba que nace derriba, podemos comezar por procurar respostas no espazo dos escritores que agroman xustamente cando Álvaro Cunqueiro estaba a se transformar nun «novo corpo limpo que sońaba co vento». Os poetas que se estrean entre finais da década dos 70 e comezos dos 80 recoñecéronse no espello de Herba aqui e acolá. O decisivo papel que este libro exerceu no desenvolvemento do proceso de renovación das linguaxes poéticas desde a súa primeira edición en 1980 é un feito reiteradamente considerado pola crítica e polas voces creadoras máis novas do momento. Dos 12 autores antologados por Luciano Rodríguez na escolma xeracional titulada Desde a palabra, doce voces ${ }^{2}$,

2 L. Rodríguez: Desde a palabra, doce voces, Barcelona, Sotelo Blanco, 1986. 
son oito os que citan a Cunqueiro como referente fundamental da súa formación literaria, con mención concreta en varios casos do derradeiro poemario do mestre. Nas respostas á pregunta do cuestionario presentado por Luciano Rodríguez relativa aos autores de incidencia formativa básica figura Cunqueiro como o máis citado, seguido por Pessoa, Borges, Celso Emilio Ferreiro e Neruda. Outros poetas de referencia son Pimentel, Rosalía, Manuel Antonio, Méndez Ferrín e os trobadores medievais; Eliot e Pound, Eugénio de Andrade e Herberto Helder; Cavafis, César Vallejo e os poetas españois da Xeración do 27.

Ramiro Fonte expresa así a súa querenza de Cunqueiro: «Fundamental é, nos meus gustos e nas miñas aprendizaxes, o último Cunqueiro. /.../ Algo terei que ver, como moitos dos aquí presentes, con Con pólvora e magnolias, aínda que a mińa profunda e máis certa debilidade como lector sexa Herba aqui e acolá». (Fonte, 1986, p. 162) Pilar Pallarés confesa: «Gostaria-me escrever como Cernuda, impresiona-me Borges, amo o Cunqueiro de Herba aqui e acolá» (Pallarés, 1986, p. 215). Manuel Forcadela matiza a función rupturista dos dous libros aos que a crítica, en mimética reiteración que non se revisa desde aquela, considera limiar do chamado cambio de rumbo dos 80, Mesteres ${ }^{3}$ de López Casanova e Con pólvora e magnolias 4 de Ferrín: «Ferrín, e moito menos Arcadio López Casanova, non romperon nada que non tivese roto Cunqueiro, por pór un exemplo, muito antes» (Forcadela, 1986, p. 243). A imprecisión da referencia temporal («muito antes») impide recońecer o momento e a obra de Cunqueiro á que Forcadela outorga ese poder de ruptura, que non pode ser Herba aqui e acolá, pero quizais si os poemas de edición dispersa ao longo de varias décadas que conformaron ese título en 1980 ou Dona do corpo delgado5, de 1950. Intensa é a devoción de Román Raña: «Simultaneamente a Borges lin a Cunqueiro e foi outra luz, a lírica contemplación do cosmos, a perplexidade carnal das palabras» (Raña, 1986, p. 295). A atracción elévase a alturas de reverencia na resposta de Paulino Vázquez: «En galego, réverence gardé envers don Álvaro Cunqueiro, sobretodo» (Vázquez, 1986, p. 339).

3 A. López Casanova: Mesteres, Valencia, Lindes, 1976.

4 X. L. Méndez Ferrín: Con pólvora e magnolias, Vigo, Rompente, 1976.

5 A. Cunqueiro: Dona do corpo delgado, Pontevedra, Benito Soto, 1950. 
En 1981, cinco anos antes da publicación da emblemática antoloxía de Luciano Rodríguez, Méndez Ferrín, que tendeu frecuentes fíos interxeracionais entre o discurso poético de Cunqueiro e a palabra dos poetas do meu tempo, falaba así en páxina de despedida:

Quero dicir que, neste día, aínda son ben poucos os que aman e comprenden o seu reinado poético. Poucos os que saben ler «Pende en que pende Penélope pensativa» e «Os chefes da casa de Gingiz» e a "Crónica da derrota das nacións». Pro, pra gloria do noso querido e recente difunto, eses poucos son xeneralmente xoves e lúcidos. Son os que teñen agora mesmo nas súas mans o facho da nosa lírica e camiñan alumando o país de cara ao novo século. (Ferrín, 1981).

A emotiva intervención xornalística enuncia a certeza dunha complicidade lectora de grupo, a dos poetas máis novos daquela hora coa poética que Cunqueiro entregaba na súa derradeira publicación lírica, un código estético e unha formulación discursiva que resultaban especialmente atractivos para os poetas dos 80. O momento era propicio para a superación de tendencias expresivas gastadas, maiormente as do realismo social, e para a procura de linguaxes poéticas máis ricas en efectos sensoriais, en propostas de intertextualidade, en tonalidades de lińa intimista, en novas formulacións do discurso épico, rumbos que anunciaban xa algúns libros editados na década anterior, entre eles o tantas veces citado título inaugural de Ferrín. Non resulta sorprendente, pois, que os poetas que daquela tiñan "nas súas mans o facho da nosa lírica» saudasen con emoción de simpatía admirativa a brillante e densa palabra de Herba aqui e acolá, que non só concentraba virtualidade de lección maxistral, función pedagóxica destinada á aprendizaxe dos máis novos, senón tamén valor especular, capacidade para reflectir as propias procuras —algunhas delas verbalizadas en discurso poemático anterior á saída dese libro- daqueles autores proclives a identificarse co magnífico artefacto lingüístico de «Pende en que pende Penélope pensativa». A aparición de Herba aqui e acolá no volume da Poesía Completa de Álvaro Cunqueiro en 1980, cuxo eco de comentarios en conversa de faladoiro lembro con nostálxica precisión, tivo ese dobre efecto: a descuberta dun referente exemplar e o recońecemento de moitos dos nosos propios sinais de identidade estética. Resulta, por outra banda, natural a declaración de simpatía de Ferrín pola nosa disposición receptiva, que coincidía coa que el mesmo, e desde claves semellantes ás nosas, viña adoptando 
desde anos atrás en relación coa obra de Álvaro Cunqueiro. Naquel momento, un dos nosos mestres máis próximos, mentres confirmaba a súa fidelidade literaria a un dos seus autores referenciais, estaba a declarar tamén a súa adhesión á importante aventura poética colectiva que irrompía a comezos da década dos 80 .

En 1991, madura xa a obra plural dos autores dos 80. Luz Pozo Garza, quen tamén permanecía atenta ao proceso discursivo da nova xeración e colaborou desde as páxinas da revista Nordés, que ela dirixía, na consolidación da nosa presenza pública, no ensaio titulado Álvaro Cunqueiro e Herba aqui e acoláb, identificou algunhas das claves da conversa interxeracional: «No "Recońecimento de Harold Godwinson” o autor harmoniza sabiamente os principios narrativos, líricos e dramáticos nunha fórmula novísima na poesía galega, na liña das formulacións estéticas máis actuais» (Pozo, 1991, p. 51). Se nesta páxina salienta a autora a proximidade entre as fórmulas construtivas utilizadas por Álvaro Cunqueiro e as que empregaban os poetas novos, máis adiante, en cambio, outorga a Herba aqui e acolá un papel de exclusividade fundacional que considero excesiva: «Os poemas pluricodificados do mindoniense constitúen verdadeiros prototipos e débense considerar como a orixe, a fonte, da nosa poesía actual» (Pozo, 1991, p. 62). A redución do curso poético múltiple dunha época ao espazo exclusivo dunha única fonte constitúe unha perspectiva de análise pouco concorde coas evidencias que podemos obter dun labor coidadoso de lecturas comparativas. Resulta posíbel detectar tendencias cuxa orixe resulte atribuíbel a determinadas solucións inauguradas por un poeta vigoroso, por un libro dotado de enerxía centrífuga. Pero concentrar naquel poeta e no seu libro o poder de xerar a complexa diversidade poética colectiva significa concederlle dimensións de forza desmesurada.

De Herba aqui e acolá proceden algúns segmentos, máis ou menos identificábeis, do discurso de determinados poetas pertencentes á xeración dos 80 . As declaracións de entusiasmo e admiración (mesmo de reverencia) ou as certezas da crítica en relación co maxisterio exercido por aquel poemario son feitos que transmiten unha información de capital importancia, insuficiente, porén, para avaliar o volume, a entidade do herdo poético que Álvaro Cunqueiro concedeu aos seus legatarios. Cómpre realizar unha coidadosa tarefa de lectura analítica dos libros daqueles poetas e tentar localizar probas significativas da influencia textual

6 L. Pozo Garza: Álvaro Cunqueiro e Herba aqui e acolá, Vigo, Galaxia, 1991. 
herdada de Herba aqui e acolá. Sería preciso, ademais, distinguir o pouso latente en tonalidades e perspectivas do eco literal, acollido con intención de diálogo intertextual ou asimilado sen conciencia de repetición. Habería que pescudar as vías a través das que chegan ao poema o universo simbólico ou as materias culturais labradas por Cunqueiro que coincidan coas dos autores estudados, non sempre aprendidas do mestre. Tal labor sobarda o horizonte das mińas intencións e os lindes desta intervención. Sinalarei só algunhas liñas de sentido e estilo de Herba aqui e acolá que puideron resultar máis atractivas para os poetas dos $80 \mathrm{e}$, en consecuencia, deixar pegadas na súa escrita. Nalgúns casos, rexistrarei probas da fidelidade, a homenaxe e o parentesco manifestos.

Luz Pozo Garza, en acertada síntese, condensa no ensaio citado:

[...] as liñas esenciais do pensamento do autor e os procedementos creativos: presencia e distanciamento do autor na obra. Dimensión intertextual dos códigos culturais. A nostalxia pola perda dos paraísos e a súa recuperación ou ensoñación. A conciencia mítica universal. As finezas do espíritu. A fascinación pola palabra. A actitude lúdica transcendente como salvación e inocencia. $\mathrm{O}$ punto de vista da conciencia artística como xerador do pulo dinámico. A polifonía do texto por enriba de calquera xénero. A mobilidade espacio-temporal. (Pozo, 191, p. 60).

Algunhas das notas que a crítica trazou para caracterizar a obra daquela xeración nos seus comezos coinciden con este resumo dos núcleos significativos e de estilo de Herba aqui e acolá. Hai, porén, unha marca definidora das tonalidades dominantes nese libro, o que a comentarista chama "finezas do espíritu», que podemos localizar tamén nalgúns dos títulos iniciais da nova xeración e na que as aproximacións analíticas do momento non repararon o suficiente. Trátase da atracción selectiva polo detalle e polo efecto sensorial, con deleite no matiz e, frecuentemente, desde unha perspectiva de emotividade nostálxica. Percibo semellantes «finezas do espíritu» en poetas como Manuel Forcadela, Anxo Quintela, Román Raña, Xavier Rodríguez Baixeras ou Paulino Vázquez, entre outros.

A preocupación polo coidado formal e musical, a labranza esmerada da palabra poética, o uso abondoso de recursos imaxinativos e de significados simbólicos, a modalización intimista e confidencial da voz do suxeito lírico e esa querenza pola sensorialidade das materias gozosas, actitudes próximas pero non sempre emparentadas nin herdadas de Álvaro Cunqueiro, conforman un dos rumbos 
iniciais máis comúns da xeración dos 80 , esa vía que unha parte da crítica actual considera tendencia esteticista ou decadentista, termos de difusa significación que se empregan sen achega de probas textuais e sen clarificación suficiente da intención e o sentido do diagnóstico.

Escasamente xustificada e documentada resulta a teimosa consideración do culturalismo, de procedencia de Cunqueiro ou doutras fontes, como clave omnicomprensiva da poesía dos 80 , cun uso desviado do termo en dirección desvalorizadora que non resulta comprensíbel. Podemos rexistrar dez ou doce libros representativos desta tendencia entre os máis de cen que se publican desde 1980 a 1990 da autoría de poetas nados entre 1945 e 1962 (entre as datas de nacemento de Manuel Vilanova e Paulino Vázquez). Non se trata agora de ofrecer un inventario completo coa correspondente enumeración de variantes estilísticas. Trátase de convidar a quen teña interese na caracterización global do labor poético dese conxunto de poetas a un exercicio de rigor e de contraste, posición que non parece presidir a declaración de Helena González Fernández, relativa aos poetas dos 90, que, segundo a súa visión «foxen do venecianismo e do culturalismo barroco (verbalismo, prefiren dicir algúns críticos e poetas do momento ben cońecidos por todos) que triunfaron entre os poetas dos anos 80» (González, 1997). A opción culturalista, de magnífica representación na poesía galega de diversas épocas, consiste no uso de referencias culturais expresas, na transparencia do intertexto, ao xeito de Méndez Ferrín ou de Álvaro Cunqueiro, por persistir na mención dos mestres, bastante proclives ambos os dous, por certo, como algúns poetas dos 80 , ao uso de estruturas lingüísticas de tradición barroca. Pero a latencia dos asuntos e temas de cultura, a actuación dun substrato significante de procedencia cultural, non constitúe marca diferenciadora de orientación estética ou liña de escola, pois esa fonte esencial de experiencias cognoscitivas constitúe - ou debería constituír - alimento necesario da poesía, sexa cal for o código expresivo escollido. Evitemos a indefinición semántica que leva á confusión entre os valores do termo especializado culturalismo cos do sintagma xenérico "poesía culta». Efectivamente, na poesía dos 80 , resulta perceptíbel ese pouso complexo de cultura universal.

Reléanse os libros editados durante a década dos 80 de autores como Xavier Rodríguez Baixeras, Alfonso Pexegueiro, Xulio López Valcárcel, Cesáreo Sánchez, Darío X. Cabana, Xavier Seoane, Pilar Pallarés, Claudio Rodríguez Fer, Xavier 
Rodríguez Barrio, Miguel Anxo Fernán Vello, Román Raña, Manuel Rivas, Xela Arias ou Ana Romaní en procura de sinais do «discurso inzado das devanditas referencias culturalistas» ao que se refire Helena González no artigo citado. Nalgúns casos, as mostras redúcense a un par de poemas onde a materia cultural constitúe clave temática ou motivo complementario. Na maioría deles, a fórmula culturalista está clamorosamente ausente.

Libros representativos desa lińa son, en cambio, Ferida acústica de río de Manuel Forcadela, As cidades da nada ${ }^{8}$ de Ramiro Fonte, Á sombra dos pavillóns 9 de Anxo Quintela e Perdendo o tempo que fuxe como Xoan Sebastian Bach ${ }^{10}$ de Paulino Vázquez, publicado o primeiro en 1982 e os tres restantes en 1983. Os poemarios de Forcadela, Fonte e Quintela non só non disimulan, senón que declaran abertamente as súa filiación. Os tres van presididos por citas de Herba aqui e acolá e desenvolven procedementos, realizan paráfrases e incorporan referencias textuais procedentes do libro de Cunqueiro. Menos abeirado a esta fonte e máis próximo á poética de Con pólvora e magnolias, o de Paulino Vázquez adopta ademais algunha das fórmulas construtivas de maior rendemento na obra derradeira do poeta mindoniense. Podemos albiscar no conxunto destes catro títulos marcas da conversa intraxeracional, pegadas da intertextualidade entre coetáneos á que me referín no comezo destas páxinas.

Creo que Manuel Forcadela foi o poeta da nosa xeración que con maior dedicación cultivou ao longo da década dos 80 o herdo das liñas culturalista e sensitiva de Cunqueiro, con tránsito posterior a rumbos de expresión marcadamente singular. Poemas de sintaxe quebrada e discurso reiterativo ao xeito do «Retorno de Ulises», citas incorporadas ao verso, permanente presenza da música como centro temático, sensorialidade de materias e substancias delicadas, intertextualidade de contido cultural con referencias nominais expresas... son algunhas das constantes de Ferida acústica de río que evocan a paisaxe lírica de Herba aqui e acolá. Álvaro Cunqueiro non chegou a coñecer o libro onde se acendía con entusiasta claridade a luz do seu herdo. Faleceu uns días despois de concertada unha

7 M. Forcadela: Ferida acústica de río, Vigo, Xerais, 1982.

8 R. Fonte: As cidades da nada, Ferrol, Esquío, 1983.

9 A. Quintela: Á sombra dos pavillóns, Ferrol, Esquío, 1983.

10 P. Vázquez: Perdendo o tempo que fuxe como Xoan Sebastian Bach, Vigo, 1983. 
cita con Román Raña e Manuel Forcadela, encontro ao que o autor de Ferida acústica de río ía levar o manuscrito case concluído.

Procedementos semellantes usa Ramiro Fonte en As cidades da nada, limiar da creación dunha mitoloxía urbana moi persoal, de ámbitos portuarios ou cabarets modernistas, de verbalización transparente e ollada culturalista que o autor vai moderando ao longo da década. Unha perspectiva idéntica á adoptada por Cunqueiro no apartado I, «As historias», de Herba aqui e acolá, o uso do eu escénico de personaxes históricos ou míticos en ficticio soliloquio confidencial, organiza o poema titulado «Enmanuel Witt atopa a don Amadeus Mozart na Quintana dos Mortos», solución que repiten outros poetas dos 80 .

Anxo Quintela pronuncia a homenaxe ao mestre na cuberta mesma do seu primeiro libro. Á sombra dos pavillóns xustifica o seu título coa cita que encabeza o volume, tirada dun poema de Herba aqui e acolá: "Quero un pavillón para as miñas mańás de neno / e outro para poder sentarme a pedir esmola á súa porta». As referencias, alusións, ecos, paráfrases e mesmo de fragmentos textuais procedentes daquela fonte conforman un poemario construído en parte ao redor do eixo de Cunqueiro, con xogos de reelaboración tan evidentes coma este: «longamente ouvimos / ese canto novelo sorrir de árvore / nos menceres tecido nos valados». Usa tamén Quintela a fórmula do eu escénico en monólogo apócrifo nun poema en que, ademais, se reutiliza unha cita de Dante que figura en Herba aqui e acolá. Modula tamén o poeta as tonalidades nostálxicas que deseñan aquel universo de materias preciosas tecido desde a perspectiva sensíbel da «fineza de espíritu».

Se Quintela concentra a luz do foco culturalista sobre o modelo de Cunqueiro, con menor profusión de antropónimos célebres que na escrita de Forcadela e Ramiro Fonte, Paulino Vázquez fai o propio ao redor da obra de Méndez Ferrín. Perdendo o tempo que fuxe como Xoan Sebastian Bach constitúe, en parte, unha declaración de homenaxe a Con pólvora e magnolias, aínda que tamén recolle achegas do patrimonio de Cunqueiro e, obviamente e como acontece na obra dos compañeiros comentados, doutras tradicións consubstanciadas na experiencia propia. Títulos de poemas como «Súplica do dean Giaccomo della Tosa por rematar os seus días no palazzo Medici-Ricardi» ou «Francesca da Rimini lémbrase da súa vida, en Fiorenza» lembran moi de preto as historias fabuladas en Herba aqui e acolá. A querenza de xénea anglosaxona de Paulino Váquez vai ir levando logo 
ao poeta por territorios estéticos persoais afastados xa das primeiras referencias formativas.

De liña parcialmente culturalista foi a produción poética de Eusebio Lorenzo Baleirón, máis próximo ao acento intimista do Cunqueiro do apartado «Vellas sombras e novos cantos» que á elaboración literaturizadora de «As historias». $\mathrm{O}$ primeiro poema de Os días olvidados ${ }^{11}$ titúlase "Álvaro Cunqueiro» e recrea, en parte, a poética do mestre. En $A$ morte presentida ${ }^{12}$ repítese a homenaxe tamén desde o título dun poema: «De como ao poeta A. Cunqueiro lle saíron flores por versos no poema». Entre os textos dispersos recompilados no volume da súa obra completa, Gramática do silencio ${ }^{13}$, lemos o titulado "Giuseppe Bálsamo, conde de Cagliostro, repara no fin dos seus días», de evidente filiación de Cunqueiro e no ronsel de composicións de semellante feitura escénica xa comentados. Román Raña, prologuista de Os días olvidados, entende que «do escritor de Mondoñedo surxe a eclosión lírica, a demorada reconstrucción de espacios estelares e de sombras interiores» (Raña, 1985, p. 22).

Outros poetas culturalistas dos 80 , que xa non se moven na órbita de Cunqueiro, aínda que nalgúns momentos poidan ser percibidos vestixios da súa escrita, son Manuel Vilanova, Vítor Vaqueiro e Vicente Araguas, voces de moi diferentes estilos e tonalidades $\mathrm{O}$ expresionismo de ritmo quebrado de Vilanova sitúase nun espazo moi distante da modulación conversacional e irónica de Vicente Araguas, probabelmente o máis expansivo entre os poetas dos 80 , no que fai a presentación de referentes culturais, de orixe mítica e histórica no caso do denso discurso épico de Vítor Vaqueiro. Algunha incursión fixen eu mesmo no territorio do culturalismo nos meus primeiros libros, onde quizais tamén se verbalice a miña participación no patrimonio herdado de Cunqueiro.

O herdo poético de Álvaro Cunqueiro, os efectos do maxisterio exercido sobre os seus herdeiros máis novos maiormente por Herba aqui e acolá —cumpriría estudar tamén o ronsel de títulos anteriores, sobre todo o de Dona do corpo delgado_-, maniféstase, pois, de xeito bastante transparente nun conxunto de varios libros de liña culturalista que afirman a voz da homenaxe ao mestre, en poemas

11 E. Lorenzo Baleirón: Os días olvidados, A Coruña, Algalia, 1985.

12 E. Lorenzo Baleirón: A morte presentida, Barcelona, Sotelo Blanco, 1988.

13 E. Lorenzo Baleirón: Gramática do silencio. Obra poética, A Coruña, Espiral Maior, 1996. 
onde é doado percibir, alén do recurso á cita e á referencia textual incorporada ao verso, o substrato da especial tonalidade lírica de Cunqueiro, o deleite nas materias delicadas, a ollada nostálxica, o intimismo temperadamente confesional. Noutros poetas non culturalistas déixase sentir tamén a sensorialidade selecta da «fineza de espíritu».

Pero, rexistradas algunhas coincidencias entre a poética de Herba aqui e acolá e os dos poetas dos 80, cómpreme deixar enunciada a seguinte evidencia: o herdo galego e universal que entregaron Ferrín ou Cunqueiro, pero tamén Celso Emilio Ferreiro, Manuel Antonio, Pimentel, Rosalía ou os trobadores medievais, por citar só os autores de noso que os poetas antologados por Luciano Rodríguez sinalan como referentes básicos da súa formación, non constitúe toda a propiedade literaria e cultural coa que traballaron desde a súa mocidade. Coa substancia das fontes, galegas e procedentes doutros territorios universais, e do labor de selección particular dos elementos que conforman tan vasto e complexo fondo común, desde a ollada e a experiencia persoal, con capacidade para a descuberta e a invención, para a creación de novas tradicións, os poetas de aquí e de agora, de todos os tempos e lugares, facemos, fan, obra propia. Estou seguro de que hai vida alén do herdo, por enriba do intertexto, á marxe das fontes. 


\section{REFERENCIAS BIBLIOGRÁFICAS}

Cunqueiro, Álvaro: Dona do corpo delgado, Pontevedra, Benito Soto, 1950.

Cunqueiro, Álvaro: Herba aqui e acolá, en Obra en galego completa, Poesía. Teatro, I, Vigo, Galaxia, 1980 Fonte, Ramiro: As cidades da nada, Ferrol, Esquío, 1983.

Fonte, Ramiro: «Cuestionario», en L. Rodríguez: Desde a palabra, doce voces, Barcelona, Sotelo Blanco, 1986. Forcadela, Manuel: Ferida acústica de rio, Vigo, Xerais, 1982.

ForCadela, Manuel: «Cuestionario», en L. Rodríguez: Desde a palabra, doce voces, Barcelona, Sotelo Blanco, 1986.

GonZÁlez Fernández, Helena: «A poesía dos noventa e a reacción contra a poesía dominante», Chineses (O Correo Galego), 3, xaneiro, 1997.

López Casanova, Arcadio: Mesteres, Valencia, Lindes, 1976.

Lorenzo Baleirón, Eusebio: Os días olvidados, A Coruńa, Algalia, 1985.

Lorenzo Baleirón, Eusebio: A morte presentida, Barcelona, Sotelo Blanco, 1988.

Lorenzo Baleirón, Eusebio: Gramática do silencio. Obra poética, A Coruña, Espiral Maior, 1996.

Méndez Ferrín, Xosé Luís: Con pólvora e magnolias, Vigo, Rompente, 1976.

Méndez Ferrín, Xosé Luís: Hoja del lunes, Vigo, 2 marzo 1981.

Pallarés, Pilar: «Cuestionario», en L. Rodríguez: Desde a palabra, doce voces, Barcelona, Sotelo Blanco, 1986. Pozo Garza, Luz: Álvaro Cunqueiro e Herba aqui e acolá, Vigo, Galaxia, 1991.

Quintela, Anxo: Á sombra dos pavillóns, Ferrol, Esquío, 1983.

RaÑA, Román: «Prólogo», en Eusebio Lorenzo: Os días olvidados, A Coruña, Algalia, 1985.

RaÑA, Román: "Cuestionario», en L. Rodríguez: Desde a palabra, doce voces, Barcelona, Sotelo Blanco, 1986. Rodríguez, Luciano: Desde a palabra, doce voces, Barcelona, Sotelo Blanco, 1986.

VÁzquez, Paulino: Perdendo o tempo que fuxe como Xoan Sebastian Bach, Vigo, 1983.

VÁzquez, Paulino: «Cuestionario», en L. Rodríguez: Desde a palabra, doce voces, Barcelona, Sotelo Blanco, 1986. 